Faculdade de Ciências Econômicas UFRGS
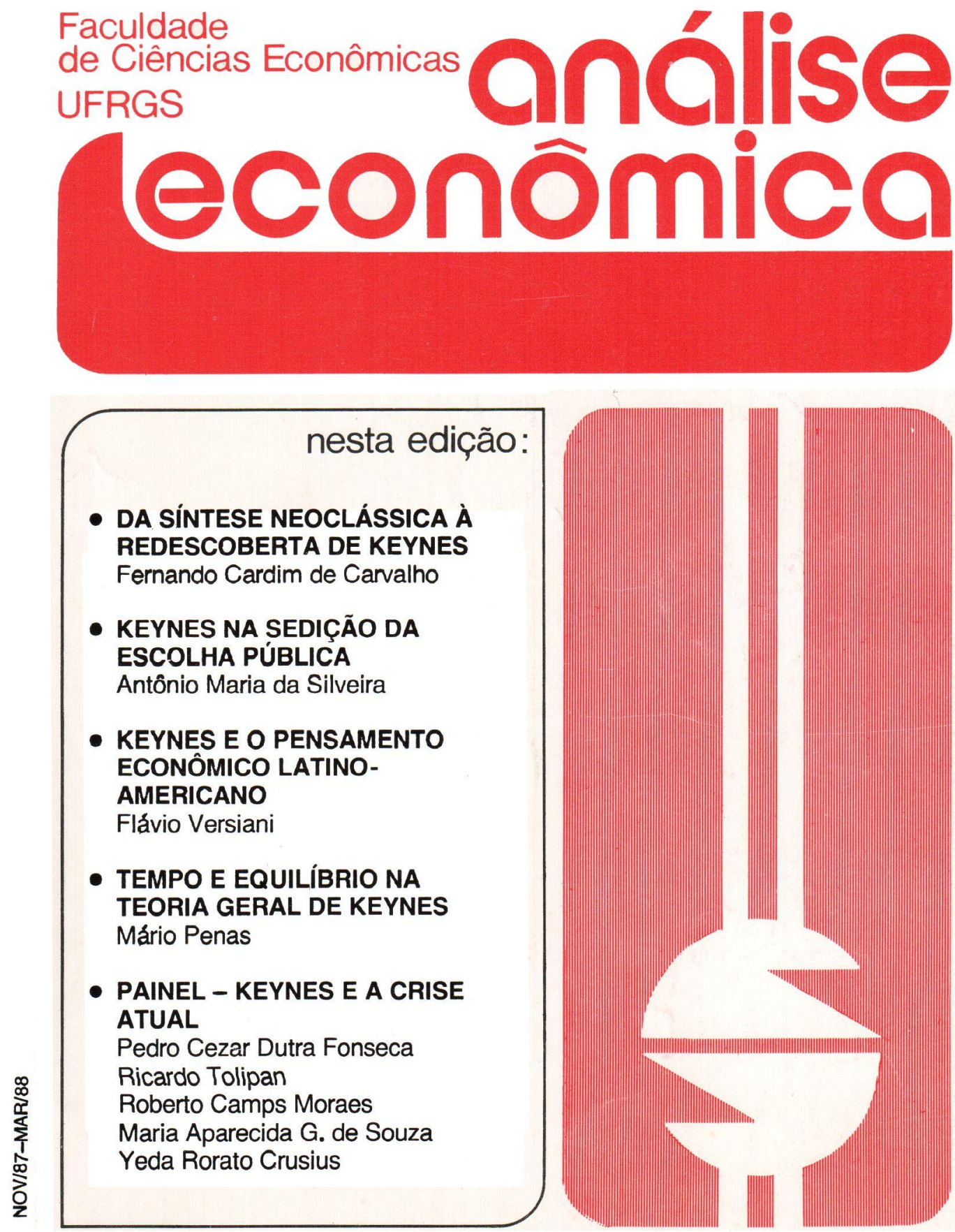
REITOR: Prof. Gerhard Jacob

DIRETOR DA FACULDADE DE CIÊNCIAS ECONÔMICAS:

Prof. Walter Meucci Nique

CHEFE DO DEPARTAMENTO DE CIÊNCIAS ECONÔMICAS:

Prof ${ }^{a}$. Otília Beatriz K. Carrion

CONSELHO EDITORIAL:

Prof. Pedro Cezar Dutra Fonseca (Presidente)

Prof. Achyles Barcelos da Costa

Prof. Carlos Augusto Crusius

Prof. Edgar Augusto Lanzer

Prof. Hernani Hickmann

Prof. Juvir Mattuella

Prof. João Rogério Sanson

Prof ${ }^{a}$ Maria Imilda da Costa e Silva

Prof. Nali de Jesus de Souza

Prof. Nuno Renan L de Figueiredo Pinto

Prof- Otilia Beatriz Kroeff Carrion

Prof ${ }^{a}$ Yeda Roratto Crusius

Prof. Paulo Alexandre Sphor

Prof. Roberto Camps Moraes

FUNDADOR:

Prof. Antonio Carlos Rosa

ANÁLISE ECONÔMICA publica dois números anuais nos meses de março e novembro. O preço da assinatura para 1988 é $\mathrm{Cz} \$ 500,00$, a ser pago através de cheque nominal para "Faculdade de Ciências Econômicas - UFRGS". Aceita-se permuta com revistas congêneres. Aceitam-se, também, livros para elaboração de resenhas ou recensões.

Toda correspondência, material para publicação, assinaturas e permutas devem ser dirigidas a:

Prof. PEDRO CEZAR DUTRA FONSECA

Revista Análise Econômica

Av. João Pessoa, $52-3^{\circ}$ andar

90.000 - Porto Alegre (RS) - Brasil 


\section{DA SINTTESE NEOCLÁSSICA A REDESCOBERTA DE KEYNES}

FERNANDO CARDIM DE CARVALHO*

Gostaria de apresentar nesta exposição a proposição de que, em Keynes, pode-se encontrar um conteúdo ou uma proposta de análise económica que é não apenas diferente das teorias existentes à sua época, como é, também, diferente do que ficou conhecido como "Economia Keynesiana".

Num certo sentido, a proposição central desta exposição - em torno da qual se reúne a "Escola Pós-Keynesiana", cujo objetivo é recuperar a proposta original da Revolução Keynesiana - é de que a principal característica da obra de Keynes - em particular, a partir de 1930, com os escritos anteriores à "Teoria Geral", tendo a "Teoria Geral" como seu momento principal e tendo alguns de seus pontos centrais explicitados nos debates de 1937 a 1938 - é uma visão de economia, no sentido de uma nova forma de encarar-se o que é essencial dentro dos processos econômicos. Isto é mais importante e representa uma inovação ou uma ruptura mais profunda do que, simplesmente, a criação de novos instrumentos de análise a serem utilizados dentro da visão dominante de economia. O que eu destacaria na obra de Keynes são os fundamentos da sua abordagem bastante diferentes das idéias correntes de então, não apenas das neoclássicas, como também das do sistema marxista e do sistema de economia clássica em geral.

Qualquer discussão em História do Pensamento Econômico, em debates como este que estamos iniciando, envolve a dificuldade de estabelecer-se um ponto de partida para a delimitação do assunto a ser discutido. Esta escolha é, obviamente, artificial e arbitrária à medida que não apenas Keynes não estava isolado do mundo e da Universidade à sua época, como também, a obra que prepara nos anos trinta é, obviamente, o resultado de seu próprio desenvolvimento intelectual anteriores 1936, incluindo, portanto, aqueles trabalhos preparados, ainda, dentro de uma visão mais convencional.

Datarei, assim, arbitrariamente, o início da revolução keynesiana

* Coordenação do Mestrado em Economia da UFF - professor do IEI/UFRJ.

\begin{tabular}{|l|l|l|l|l|}
\hline ANÁLISE ECONÔMICA & ANO 6 & № 9 & NOV/87-MAR/88 & p.3-21 \\
\hline
\end{tabular}


pelos escritos dos anos trinta de preparação da Teoria Geral, basicamente produzidos nos anos 32 a 34. Para tanto, enfocarei alguns textos que se tornaram disponiveis apenas a partir dos anos setenta com a publicação dás obras completas de Keynes. Basicamente, são os volumes quie contêm não apenas toda a correspondência referente à Teoria Geral como também seus e rascunhos os textos e cartas escritos após sua publicação e que sustentam o tipo de proposição que me propontio a expor. ${ }^{-} \mathrm{O}$ que se tornou conhecido como Keynesianismo, chamado de "revolução keynesiana", nos livros-textos, não corresponde, efetivamente, a estes textos, mas diz respeito apenas, de forma relativamente distante, à própria "Teoria Geral". O que farei, antes de mais nada, é uma breve colocação de que, nas suas linhas mais gerais, compôs a "Teoria Geral" enquanto estrutura para, a partir dál, tentar ver de onde surgiu essa interpretação que acabou tornando-se predominante. Ao final, contrastarei esta construção com as propostas originais do próprio Keynes.

A "Teoria Geral", como é sabido, compōe-se, basicamente, de quatro grupos de afirmações (ou cinco se incluirmos os capítulos finais, que são digressōes de Keynes aplicando a teoria que ele acabava de propor a problemas mais específicos). 0 primeiro bloco constitui-se de uma crítica ao que Keynes denominava "Escola Clássica", hoje em dia mais apropriadamente chamada Escola Neoclássica. Esta crítica, essa, que se desenvolve em torno das definições do funcionamento do mercado de trabalho (cap. 2 da Teoria Geral). Estas teorias repousam no pressuposto de que aos trabalhadores é possivel regular o salário real de tal forma que, quando surgisse desequilibrios no mercado de trabalho - como, por exemplo, desemprego - estes desequilibrios poderiam ser removidos pelo ajuste de salários, por iniciativa dos próprios trabalhadores. Keynes utiliza-se desta discussão para criticar a teoria que ele denomina de "Teoria Clássica do Emprego". Nesta crítica, Keynes conclui pela nấ-validade de, pelo menos, parte dos postulados que sustentam a capacidade auto-reguladora do mercado de trabalho e a inevitabilidade do pleno emprego. Em conseqüencia, Keynes passa a construir uma teoria alternativa composta de três blocos (caps. 4 até 18 da Teoria Geral) 0 próprio autor, no capítulo 17 , junta estes blocos dentro do que ele chama de "Teoria Geral do Emprego". Obedecendo a critérios de sequência lógica, Keynes propốe um processo de determinação do nível de emprego em três passos: 1) conhecendo-

1 - Veja-se Keynes, John Maynard, The Collected writings of John Maynard Keynes. Vols. XIII, XIV e XXIX. London: MacMillan, 1973, 1973 e 1979. 
se a oferta de moeda, ou seja, o estoque de moeda existente na economia, e as preferências do público em relação a liquidez, isto é, em quais ativos a população prefere manter sua riqueza através do tempo, determina-se a taxa monetária de juros; 2) dados a taxa monetária de juros e o estado de expectativas de longo prazo que englobam as expectativas de lucratividade dos investimentos de capital real, determina-se o volume de investimentos do periodo; 3) dado este volume de investimentos e dada a propensão e consumir, isto é, as preferências intertemporais dos consumidores, determina-se o nivel de renda que, no curto periodo marshalliano, dentro do qual opera Keynes, determina também, o nivel de emprego.

Para Keynes existe um processo de causalidade seqüencial no qual quatro dados resolvem todo o modelo; um dado é institucional, fixado pelo Banco Central que é a oferta de moeda; ${ }^{2}$ e três são variáveis que Keynes chama de "psicológicas" que são: 1) a preferência pela liquidez; 2) a eficiência marginal do capital ou mais especialmente o estadọ de expectativas a longo prazo; 3) a preferência intertemporal ou propensão a consumir. Com estes dados, Keynes determina a taxa de juros, o nivel de renda e o nível de emprego, construindo a "Teoria Geral" em torno das definições de cada um desses passos.

Um bloco da "Teoria Geral" é dedicado à determinação e à explicação do que é a propensão a consumir ou função consumo. O segundo bloco é o da preferência pela liquidez e o terceiro o da eficiência marginal do capital. Portanto, os capítulos e as proposições que compõem a "Teoria Geral" podem ser agrupados nestes três blocos onde se encontra sistematizado o núcleo de toda a teoria econômica que se tornou dominante até o final da década de cinqüenta. A partir daí, esta teoria passa a ser substituida por alternativas como a de Milton Friedman e, mais recentemente, pelas escolas chamadas novoclássicas ou Escolas de Expectativas Nacionais.

Nos anos quarenta surgem a Síntese neoclássica - termo este usado por Samuelson para indicar a recuperação das proposiçōes keynesianas dentro do arcabouço teórico tradicional da teoria econômica. Entende-se por arcabouço teórico tradicional o que está nos modelos de equilíbrio geral concebidos a partir de Walras. ${ }^{3}$ A Síntese Neoclássi-

2 - Isto não significa necessariamente tomar partido no debate entre os que acreditam na endo ou exogeneidade da moeda. Sobre isso, ver S. Weintraub, Keynes, Keynesianos and the monetanists, Philadelphia, University of Pennsylvania Press, 1978, e J. Kregel, "Constraints on the Expansion of out put and Enploument real or monetary?" Journal of Post Keynesian Economics, Winter $1984 / 5$.

3 - L. Walras, Element of Pure Economics, London: George Allen and Unwin, 1954.

4 - Para uma discussão das leis de Say e de Walras e uma crf́tica desta distinçăo, ver A. LEIJONHUFVUD. On Keynesian Economics and the Economics of Keynes, New York: Oxford University Press, 1968. 
ca desenvolveu-se como uma tentativa de compatibilização entre os resultados obtidos por Keynes na Teoria Geral (como, por exemplo, a possibilidade de equilíbrio com desemprego), e um modelo teórico em cuja formulação iniciais tais situadas não eram admissiveis admitidos. Um dos postulados do modelo de equilíbrio geral, entre outros, é a validade da lei de Say ou, numa versão um pouco diferente, a lei de Walras. ${ }^{4}$ Como compatibilizar este modelo visto até hoje, como o centro da teoria dominante em economia ${ }^{5}$, com os resultados obtidos por Keynes na Teoria Geral? Este processo de conciliação é o processo de formação da Sintese Neoclássica. Quando, porém, ficou demonstrado a impossibilidade desta conciliação a própria sintese desaparece.

A sintese surge, não por acaso, com Hicks em 1937, num texto mais citado do que lido, denominado "Senhor Keynes e os Clássi$\cos ^{\prime \prime}{ }^{6}$ Este texto, bastante familiar a qualquer estudante de economia, cria um modelo que é o da IS-LM, sendo um modelo bastante atraente pela facilidade com que qualquer coisa, qualquer efeito da economia, pode ser encaixado em alguma de suas curvas. Sua atração advém da idéia de que, em se conhecendo o modelo, sabe-se operar-se a economia como um todo: pode-se, por exemplo, estudar repercussões de umas variáveis sobre as outras.

Hicks, não por acidente, é o introdutor da teoria walrasiana do Equilíbrio Geral na Inglaterra.

Hicks, na década de trinta, causou uma revolução em termos de Teoria Econômica de Língua Inglesa. Sua influência foi tão, ou mais importante, do que a própria "Teoria Geral". Em parte por coincidência, como vou tentar propor, em parte deliberadamente, o que acabou sendo conhecido como revolução keynesiana é, efetivamente, um desenvolvimento das idéias de Hicks. Em um de seus livros mais recentes, chamado "Crise da Economia Keynesiana", Hicks reconhece, apesar de sua conhecida modéstia que muito do que se atribui a Keynes deriva mais dele, Hicks, do que ao próprio Keynes. ${ }^{7}$

O artigo de 1937 é um momento importante da história do pensamento econômico deste século. Sua intenção é simples e modesta. Faz Hicks a seguinte proposição: Keynes, quando apresenta a "Teoria Geral" enviesa a análise, ao fazer uma crítica aos clássicos sobre a operação do mercado de trabalho, mas passando, depois, a defender uma teoria de taxa de juros, uma de investimentos e outra de consu-

5 - Cf. F.H. Hahn, Money and Inflation, Cambridge: The Mit Press. 1983.

6 - J.R. Hicks, "Mr. Keynes and the Classics: A Suggesteo Interpretation" reimpresso em J. Hicks, Critical Essays in Monetary Theory, Oxford: Oxford University Press, 1973.

7 - Veja também a avaliação de R.W. Clower no Prefåcio. Sir John Hicks, The Crisis in Keynesian Economics, New York: Basic Books, 1974. 
mo. Propõe então Hicks que, para estabelecer ou a novidade a superioridade da teoria keynesiana, Keynes deveria ter comparado os modelos dentro dos mesmos campos, ou seja, em que a função consumo de Keynes é superior à clássica, onde o esquema de taxas de juros proposto é diferente do clássico e assim por diante. Foi com a finalidade de se estabelecer as comparações que o artigo de 37 foi escrito. Hicks abre o artigo expondo estas idéias, passando a estabelecer uma comparação da forma que ele acredita ser a mais adequada. A partir dai, propõe um modelo que comporta três variantes: um que chama de modelo clássico, e os outros dois de tipo keynesiano.

Este modelo é definido por três equações sendo em duas equações comportamentais e uma de equilíbrio. A primeira equação comportamental na variante clássica é a de demanda por moeda, em que se utiliza a teoria quantitativa, na qual a demanda por moeda é proporção estável da renda nominal, isto é, ela varia com a renda e não, como proporia Keynes, mais tarde, prioritariamente, com a taxa de juros. A segunda equação clássica coloca o investimento em bens de capital como função da taxa de juros; e a terceira equação do modelo clássico é a condição de equilíbrio, onde os investimentos, devem ser iguais ao volume de poupança, sendo que esta poupança é determinada pelo nivel de renda e taxas de juros. Nota-se que Hicks introduz, pela porta dos fundos, o nivel de renda na função poupança como sendo uma característica do modelo clássico. Diz ele: como os clássicos trabalham, normalmente, com a renda dada, esta não precisa ser, via de regra, especificada. Mas, prossegue, os clássicos concordariam, certamente, que a renda tem influência quando for variável. Esta estrutura contrastada com o que ele chama de Modelo Keynesiano Especial, em que a demanda por moeda é apenas uma demanda especulativa, ou seja, uma função de taxa de juros.

A função investimento continua sendo uma função da taxa de juros, e a condição de equilíbrio é investimento igual a poupança, sendo esta determinada apenas pela renda. Hicks afirma que este modelo seria profundamente diferente do modelo clássico, pelo menos na primeira e segunda equações, a sela em relação à demanda de moeda e a determinação da poupança. Keynes, conforme Hicks, na verdade não defenderia estes princípios, apresentados em pontos esparsos da Teoria Geral, simplesmente, para dramatizar certos contrastes.

O módelo da "Teoria Geral" mesmo seria composto por três equaçōes diversas daquelas do modelo especial. A demanda por moeda seria funçāo do nível de renda e da taxa de juros, ou seja, da demanda para transações além da demanda especulativa; $e$, também, da função investimento e poupança como determinados anteriormente. 
Resumindo, a única diferença entre Keynes e a "Escola Clássica" estaria em que nos clássicos a taxa de juros influencia a função poupança, enquanto em Keynes esta influência é negligenciável. Todas as outras funções seriam, basicamente, semelhantes.

Propõe, ainda, Hicks outro princípio de consequiências profundamente importantes. Diz ele: numa economia em que a oferta de moeda é fixa e o eqüilíbrio do nivel de preços é proporcional a oferta de moeda, uma vez determinada a oferta de moeda, com velocidade constante, o nivel de preço estará fixo. Em uma economia deste tipo, se subirem os salários nominais e os trabalhadores conseguirem allcançar remunerações mais elevadas, fatalmente os lucros e a taxa de emprego reduzir-se-ão. Em uma economia com rendimentos decrescentes, como é o caso assumido normalmente, quando o nưmero de empregos diminui, os salários reais sobem. Com menos pessoas trabalhando, a produtividade marginal e, assim, o salário real, è maiof: Deste modo, quando sobem os salários nominais sobem támbém os reais, devido a este efeito sobre a taxa de empregos. Portanto não há necessidade de discutir-se as duas variáveis, se elas variam juntas e na mesma direção: basta escolher uma. Hicks escolhe o sálário real; desaparecendo, com isto, com um dos temas $e$ variáveis fundamentais de Keynes, que é o comportamento, o papel e a influência do salário nominal. Para Keynes, o salário nominal é a base de um tema de valores, já que todas as grandezas são avaliadas em termos de sálários nominais: 8

Na teoria de preços keynesiana, salários nominais são a base do sistema. No entanto, eles simplesmente desaparecem da síntese neoclássica pela afirmação de que, com essa variável, não se acrescenta nenhuma informação. Pergunta-se, então: por que não trabalhar con salário real, que é a variável tradicional?

A intenção de Hicks nesse artigo é mais de reinterpretação do que esvaziamento da "Teoria Geral" sendo esta reinterpretação compreendida no sentido da teoria positivista, ou seja, de nova contribuição. Para Hicks, a função investimento, tanto no modelo clássico, como no keynesiano especial, ou no keynesiano geral, é função da taxa de juros, utilizando-se inclusive a mesma notação nas três variantes. No modelo clássico essa relação dá-se via função da produção

8 - Veja-se Keynes, The General Theory of Employment, Interest and Money, Nen York, Horbirges, 1964; A Trestise on Money, CWJMK, volv. V e VI, London: MacMillan: 1971; P. Davidson, Money and the Real World, London: MacMillan, 1978; R.F. Kahn, "Some Aspects of the Development of Keynes s Thought, Journal of Economic Literature, $1978 \mathrm{eC}$ próprio Hicks, The Crisis, cft.

9 - Veja-se Keynes, The General Theory, e o artigo de 1937, "The General Theory of Employment", em CMIMK, vol. XIV. 
que é determinada, naturalmente, pela dotação efetiva de fatores $\mathrm{e}$ do conhecimento tecnológico correntes.

Para Keynes, por outro lado, a decisão de investimento relacionase com as taxas de juros por razōes completamente diferentes, já que está relacionada ao estado de expectativa de longo prazo, cujas relaçōes (se houver) com uma possivel função de produção corrente, são extremamente tênues. ${ }^{9}$

No entanto, formalizado o problema da forma como faz Hicks na teoria neoclássica, tem-se a tecnologia corrente como determinante e, portanto, a funçāo de produção. Os investimentos, então, variam com os juros. Keynes toma como dado o estado de expectativas de longo prazo e, portanto, o investimento também varia com os juros. A notação assim é, efetivamente a mesma ( $\mathrm{l}=\mathrm{i}$ (i) ) nos dois modelos: 0 investimento é uma função i da taxa de juros. Com isto, porém toda a discussão levantada por Keynes ao longo de vários capítulos, de como os investimentos são decididos e o resultado obtido, simplesmente desaparece. ${ }^{10} \mathrm{~A}$ importância disso está na própria dinâmica do modelo. $\mathrm{O}$ investimento que se discute, ao longo da função neoclássica, é chamado investimento em aprofundamento de capital, vinculado ao fato de, ocorrendo uma mudança de preços relativos, esperar-se uma mudança na relação capital/trabalho, a proporção entre fatores de produção.

O investimento discutido em Keynes é o chamado "alargamento de capital". Ele não está preocupado na relação capital/trabalho, mas com a despesa em investimento que envolve o crescimento do emprego. Em termos de emprego, a despesa em investimento tem uma implicação que no modelo da função de produção não existe.

A IS-LM, na verdade, cumpre a função que Hicks esperava, isto é, formalizar, de maneira tal, que se tenha exatamente os modelos nos mesmos termos ou que se possa definir todas as teorias nos mesmos termos. Assim sendo, todo o ponto da revolução keynesiana se resumiria a que variável acrescentar e onde acrescentar a uma estrutura comum. Isto, na verdade, trata-se de uma questão empírica. Os poupadores podem reagir às taxas de juros ou não. Talvez reajam no Brasil, talvez não reajam na Inglaterra. Trata-se, então de uma questão simplesmente de econometria e não de uma revolução teórica.

Como resultado disto, em 1937 se obtém uma estrutura formal, comum, porém sem conteúdo. Ou seja, foram esvaziadas as funções

10 - Compare-se com The General Theory, caps. 5 e 12.

11 - Na verdade, não exatamente qualquer mensagem, mas apenas aquelas de caráter estático.

12 - J.R. Hicks. Vahe and Capital, and edition, Oxford: Oxford University Press, 1946. 
tanto keynesianas quanto clássicas. Foram reduzidas, na verdade, a um jogo de sinais. Podemos compará-lo a IS/LM, na sua concepção, a um táxi que tem capacidade de levar qualquer mensagem a qualquer lugar. ${ }^{11}$ Definir qual seria esta mensagem é o segundo momento de nascimento da síntese neoclássica.

A síntese neoclássica surge, na verdade, dois anos depois da IS-LM, com o próprio Hicks, em Valor e Capital. ${ }^{12}$ A visão de Hicks nesta obra é radicalmente oposta à apresentada aqui. No entanto, mesmo das críticas esta reconhece ser Hicks um dos autores de maior solidez e importância na teoria econômica deste século.

Valor e Capital é, certamente, a obra-prima de Hicks. Este livro vem preencher o vazio que a IS-LM criou. Tinham-se os desenhos, tinham-se os sinais. Agora, "Valor e Capital" dá o conteúdo desses sinais. Há quatro discussões centrais em "Valor e Capital" que acabaram se transformando na "economia keynesiana".

A primeira é que a relação investimento/taxa de juros passa a ser definida via função de produção, passando a ser o chamado "aprofundamento de capital", uma relação real entre proporções de fatores e custo relativo dos fatores, representados por juros e salários. Essa taxa de juros é, agora, real, e não mais monetária. O investimento é o volume de bens de capital novos, supondo que haja uma medida fisica qualquer, que se altera em relação ao número de trabalhadores em operação. Toda a análise de expectativas que faz Keynes na Teoria Geral - para ele crucial, como era em toda a tradição marshalliana -, simplesmente, desaparece. Na função de produção não há espaço para expectativas, é simplesmente tecnologia e dotação de fatores. ${ }^{13}$ Portanto, a função investimento perdia o caráter instável. Para Keynes, a principal causa dos ciclos econômicos. Era exatamente, a flutuação de investimentos, calcada na flutuação de expectativas. ${ }^{14}$ isto desaparece à medida que uma função de produção, quase que por definição, flutua muito pouco. Ela simplesmente cristaliza o conhecimento de uma época. ${ }^{15}$ Este conhecimento avança pela margem, em condições normais, não por saltos.

A segunda grande mudança diz respeito ao modelo monetário. Hicks observa que quando Keynes introduz a demanda por transações, no seu modelo geral, já tinha feito uma abertura à visão convencional. Até porque a visão convencional da teoria quantitativa, especialmente

13 - Para Keynes, mesmo uma decisão de curto perlodo, como a de quanto produzir, nunca era visto como apenas "teórica". Veja-se, a propósito, a discussão do "custo de uso" na Teoria Geral.

14 - Ver o artigo "The General Theory of Employment", cit.

15 - Para uma dada estrutura de preços dos fatores. 
nas suas versões mais sofisticadas, certamente na versão wickselliana, não dizia, propunha que a demanda por moeda fosse exclusivamente determinada pelo nível de renda. A teoria dos fundos emprestáveis relaciona uma taxa natural de juros com taxas de juros de mercado e mostra que a demanda por moeda varia, pelo menos no curto periodo, em função da diferença entre as duas taxas de juros. Ou seja, numa visâo inspirada por Wicksell era relativamente simples compatibilizar, pelo menos em termos formais, a preferência pela liquidez, proposta por Keynes, com a visão anterior a ele. No "Valor e Capital" toda a discussão monetária se destina ao aprofundamento teórico destes argumentos, propondo que a oposição proposta por Keynes à identificação de sua teoria monetária com a teoria de Wicksell é, na verdade, resultado de uma certa falta de clareza com relação ao modelo em si. Segundo Hicks, seja qual for o modelo escolhido, se obterá, em equilíbrio geral, o mesmo resultado. Sendo indiferente a escolha, meIhor seria ficar com a teoria já desenvolvida, de longa tradição, inclusive, pela escola de Estocolmo, que tinha como corolário colocar a taxa de juros no longo prazo como função da produtividade da economia e da propensão da população a poupar. Com isso, portanto, desaparece todo o segundo campo em que Keynes acredita-se que expectativas, incertezas e coisas do tipo fossem fundamentais para discussão da escolha de ativos, em particular, escolha de ativos líquidos, escolha de ativos monetários vis-a-vis ativos reais. Ou seja, voltou-se à teoria de que as pessoas não retém moedas; as pessoas demandam é crédito. "Eu quero moeda porque tenho que comprar alguma coisa". Dentro disto tem-se um corpo de teoria em que se demanda moeda se se tem investimentos lucrativos a serem feitos. Mede-se isso via função de produção. Ou seja, não há qualquer espaço para expectativas dentro desse modelo. E, simplesmente, uma questão de ter-se informação sobre o que está ocorrendo e as possibilidades técnicas de produção.

Há duas coisas que são, ainda, importantes: primeiro Hicks cria o chamado método de "equilibrio" temporário. Um dos grandes problemas que a teoria de equilibrio geral sempre teve e tem até hoje como atestam outros modelos, do tipo Arrow/Debreu, é de como lidar com uma economia que se move. Hahn costuma dizer que a teoria do equilíbrio geral é muito boa para estados, mas não consegue discutir processos. ${ }^{16}$ Pode-se discutir o que é uma economia em equilibrio, mas não se pode explicar como chegar a ele. Hicks cria um meio de

16 - F. Hahn, Equilibrium and Macroeconomics, Cambridge: The Mit Press, 1984. Vejase também, Joan Robinson, What Are the Questions, Asmonk: ME. Shaspe, 1980 e "Keynes and Ricardo", Journal of Post Keynesian Economics, l, i, Fall 1978.

17 - A "semana" e o periodo de produção. 
obter-se isso, com o chamado modelo de "equilíbrio temporário", um modelo extremamente influente, um tipo de análise de periodo, usado, até hoje, em macroeconomia. Uma caracteristica desse método, é que os horizontes de decisões, são muito curtos. Conforme o próprio Hicks, toma-se décisões numa "segunda-feira" para obter-se resultados na "segunda-feira" seguinte, ${ }^{17}$ correspondendo que Keynes shamou na "Teoria Geral" de expectativas de curto periodo. O método não dá conta, porém, de expectativas de longo periodo, que só emergem no momento de discutir-se o quanto investir porque as decisões de investimento atingem um número muito graı ide de periodos.

Finalmente, a última caracteristica crucial do "Valor e Capital" é o fato de Hicks discutir, rigorosamente, a base teórica, dentro da teoria convencional, de efeitos, como o chamado efeito multiplicador. Como é sabido, o efeito multiplicador é a propagação de um choque exógeno de demanda através da propensão a consumir. Um choque exógeno pode ser um gasto público ou um investimento, ou seja, qualquer gasto que não seja induzido pela própria renda. Ele propaga-se porque os agentes econômicos, ao invés de adaptarem-se aos aumentos da demanda aumentando os preços, aumentam, isto sim, quantidades produzidas. Ao fazer isto, eles dão emprego a outras pessoas que, por sua vez, causam um aumento secundário de demanda que se repetirá até seu esgotamento. Se, desde o início, houvesse um aumento de preços, o ajuste seria obtido, simplesmente, por um aumento do nivel geral de preços. $O$ número de empregos nāo cresceria nem ocorreriam efeitos secundários. Em outras palavras, não haveriam efeitos-renda: a composição de renda real poderia se alterar, mas não o seu volume.

$O$ efeito multiplicador nada mais é do que uma variante do efeito-renda. ${ }^{18}$ Hicks, no "Valor e Capital" formaliza o efeito-renda, denominado por ele como falsas trocas feitas a preços fora de equilibrio, descartando, porém, em um parágrafo, a importância destes efeitos. Com isso, Hicks descartou toda a discussāo teórica sobre o sentido do multiplicador.

Em sintese, o que a obra de Hicks faz é preencher o espaço vazio deixado pela reconstrução da Teoria Geral através de IS-LM. Na verdade, Hicks primeiro retirou Keynes do campo, com a IS-LM, para depois, ele próprio, entrar nele, com o Valor e Capital. A substituição de Keynes por Hicks foi facilitada por alguns fatores secundários. Hicks dentro do pensamento dominante, é, analiticamente, um dos autores mais sólidos que tivemos neste século. Se compararmos a vigorosa teorização de Hicks com as observaçōes às vezes impressionistas

18 - Este tema é bem explorado por A. Leijohnufvud, On Keynesian Economics, cit. 
e dramáticas de Keynes, torna-se óbvio porque a preferência dos convencionais recaia em Hicks. Seus argumentos tinham premissas, desenvolvimento e fim, rigorosamente ligados e desenvolvidos à base de pressupostos familiares ao universo neoclássico.

Ao examinarmos a obra de Hicks veremos que seu trabalho é extremamente metódico, tendo o cuidado, por exemplo, de estabelecer o mesmo número de páginas para os diversos capítulos de seus livros. Esta disciplina aplicada a uma exposição de um assunto extremamente complexo, como era a formulação da teoria geral de emprego, deu, obviamente, a Hicks muitas vantagens. Comparando a "Teoria Geral", que é um livro de difícil leitura e, até certo ponto, obscuro em termos de teoria, ao Valor e Capital, veremos que neste a teoria está tecnicamente melhor acabada. Ela ocupa o espaço de Keynes, mas com um senão: o problema do desemprego desaparece novamente. Ou seja, o desafio lançado por Keynes à Teoria Clássica desaparece. Em outras palavras, ao refinar-se toda a análise, ficou-se sem o ponto que se queria discutir. A saida para o impasse vem de outro Prêmio Nobel, Franco Modigliani, em 1944, com a publicação de um artigo sobre preferência pela liquidez. ${ }^{19}$ Neste artigo ele defende a idéia de que o desemprego existe porque os salários não caem ou, alternativamente, a taxa de juros não cai. Dentro do esquema anterior a Keynes, só havia uma possibilidade de explicar-se desemprego. Em algum ponto do sistema os mecanismos de ajuste teriam de faihar. Algum mecanismo equilibrador precisaria ser impedido de operar. Uma explicação possível era dizer que os mercados operam em concorrência imperfeita. Uma das proposições mais conhecidas deste modelo é a de que é possivel ter-se subutilização de recursos nestas condições. Por exemplo, se o mercado de sapatos é imperfeito e sustenta um preço muito alto, sobrarão, fatalmente, sapatos em relaçāo a uma medida de plena capacidade. $^{20}$ Se não houver nenhum mecanismo que force o preço dos sapatos para baixo, sobrarão sapatos.

Uma saida, de vida posterior mais ou menos ilustre, propõe que não se apele à concorrência imperfeita porque existiriam em certos pontos do sisterna e, em particular, no mercado de trabalho, formas de ilusão monetária. Ou seja, os trabalhadores confundiriam salários nominais com salários reais e isso impediria o sistema de ajustar-se. Também no mercado de capitais haveria uma certa confusão entre a

19 - F. Modigliani, "Liquidity Preference and the Theory of Interest and Money", Econometria, 1944.

20 - Sobre a relação concorréncia imperfeita e capacidade ociosa veja-se J. Steindl, Maturity and Staquation in American Capitalism, New York, Monthly Review Press, 1976. 
taxa nominal e a taxa real de juros impedindo, novamente, a adaptação da economia.

O argumento da ilusão monetária teve uma biografia posterior muito extensa. Em 1968, por exemplo, Milton Friedmann em seu célebre artigo sobre a curva de Phillips usa o argumento de que os trabaIhadores sofrem de um tipo de ilusão monetária que vai sendo perdida aos poucos. A própria curva de Phillips é explicada por ele em cima de um tipo de ilusão monetária. ${ }^{21}$ Também nas expectativas racionais, na versão de Lucas existe, em algum grau, essa proposição. Assumir ilusão monetária significa assumir que o agente é irracional, ou seja, o agente econômico não consegue distinguir o que é bom para ele, confundido moeda com produto. A condição de racionalidade, porém, serve tanto para a teoria clássica como para outras correntes, pois o comportamento de um agente irracional não poderia ser generalizável e portanto descrito teoricamente. Postulas, como Modigliani, a rigidez de salários ou de juros só poderia representar uma volta às formas prékéynesianas de explicação do desemprego. À reconstrução do mundo neoclássico por Hicks seguiu-se assim a restauração da visão clássica do desemprego.

O último passo, para complementar a sintese, foi dado por Patinkin, principalmente através de sua obra "Moeda, Juros e Preços". 22 Neste livro Patinkin explora, teoricamente, o chamado Efeito Pigou, demonstrando rigorosamente as observações de Modigliani, em um modelo de equilibrio geral. $O$ efeito Pigou parte de que as pessoas gastam em função da sua riqueza real. Portanto, ao cairem os preços, o valor real da riqueza monetária, das bolsas dos consumidores, sobe. Portanto, por mais que não se queira consumir, os preços baixos atrairão os consumidores de volta ao mercado. No limite, se o PNB custar um centavo, todo mundo compra e o desemprego fica eliminado. $O$ efeito Pigou, em relação ao qual o próprio Patinkin não reconhecia qualquer utilidade prática, não tem qualquer pretensão política. Porém, em termos de teoria, completa o proposto por Modigliani, ou seja, de que em certos momentos, certos preços são rígidos e por isso o desemprego. Via efeito Pigou, sempre seria possível aicançar-se o equilibrio geral com pleno emprego, etc.

A síntese neoclássica esgota-se ai. A partir deste ponto a revisão neoclássica do sistema keynesiano entra em decedência. $O$ esgota-

21 - Ampla crftica à curva de Phillips é realizada por S. Weintraub, Keynes, Keynesians, cit. e A. Leijonhufvud, Information and Coordination. Oxford: Oxford University Press, 1981.

22 - Don Patinkin, Money, Interest and Prices, New York: Harper and Row, 1965. Veja-se também D. Patinkin, "Price Flexibility and Full Employment", in M.G. Mueller (ed.), Redings in Macroeconomics, New York: Holt, Rinehart and Winston, 1971. 
mento teórico se dá nos anos 50 , precedendo o esgotamento político de keynesianismo neoclássico dos anos 60. A posição dominante é perdida primeiro por Friedmann (naturalmente, estou enfatizando a mudança dentro do pensamento norte-americano, predominante dentro da economia) que assume a liderança teórica em macroeconomia ao final dos anos 50 . Em termos teóricos, a síntese tratava-se de muito discurso para uma idéia tão antiga, ou seja, a idéia da rigidez e imperfeição da competição em certos mercados.

Anos mais tarde, dá-se o esgotamento do projeto político da síntese. Este esgotamento dá-se por razōes em pouco diferentes da anterior. O modelo de Hicks, foi reforçado em 1947 por influente artigo de Samuelson.23 O modelo de Samuelson (curva de 45으, solução de nivel de emprego, função consumo somando-se a gastos de governo, de investimentos, etc.), definido inteiramente em termos reais, tornouse modelo a partir do qual se construi muita coisa em macroeconomia. Com isso, as duas matrizes formais da síntese neoclássica - modelos da IS-LM e o modelo de 45 graus de Samueison - foram modelos estritamente reais. Neles, uma situação de inflação só surge enquanto fenômeno real, ou seja, causada por um excesso de demanda real. Não há espaço para tratar-se de variáveis monetárias como salários monetários, preços absolutos e explorar a influência das taxas monetárias de juros.

Toda a teoria político-econômica keynesiana resume-se a uma idéia bastante difundida, porém absolutamente incorreta, de que Keynes teria demonstrado a inutilidade da política monetária e a força da política fiscal. ${ }^{24}$ Portanto, a revoluçāo keynesiana seria a vitória do fiscalismo. Por mais superficial que seja a leitura da sua obra, durante e depois da Teoria Geral vê-se que a análise da política monetária era, absolutamente, central às preocupação de Keynes. O último artigo de Keynes, editado já depois da sua morte, é sobre o balanço de pagamentos americano. Trata-se de uma defesa da necessidade de uma política monetária que obtivesse baixas taxas de juros de longo período. Tudo isso desaparece dentro da síntese, pois simplesmente não há o espaço para essas variáveis. Portanto, só podia acontecer, como aconteceu nos anos sessenta, que, em algum momento, a composição

23 - P. Samuelson, "The Simple Mathematics of Income Determination", em M.G. Mueller, cit.

24 - O absurdo de atribuir-se tais idéias a Keynes é demonstrado mesmo pelo mais superficial exame das obras de Keynes. Para uma discussão do ponto veja-se P. Davidson, Money and the Real World, cit; $H$. Minsky, Stabiliziny an Unstable Economy, Yale University Press, 1986; J. Kregel, "Le Multiplicateur et la Préférence pour la liquidité: deux aspects de la théorie de la demanda effective", em A. Barrere (ed.) Keynes Aufourdhui, Paris: Economica, 1985. 
de instabilidade de emprego com instabilidade de preços - a chamada estagflação - criasse um problema para o qual a teoria dita keynesiana não oferecia saída. Ou seja, enquanto se tinha apenas o problema do desemprego, nos Estados Unidos, por exemplo, com o indice de preços aumentando menos de um por cento a cada três ou quatro anos (um aumento Friccional), como nos anos 50 se tinha um problema que a Sintese podia resolver. A proposição de que gastando-se mais reduzse o desemprego sem outras implicações era, até, aparentemente, verossimil. Nos anos 60 , quando a realidade coloca novos problemas, como a estagflação, a síntese não sabe onde introduzi-los. Por mais que se tente sofisticar o esquema de $45^{\circ}$, a IS-LM não há como introduzir de modo significativo esse tipo de situação.

O keynesianismo, então, entra em colapso. No final dos anos 50 , desaparece das universidades, primeiramente substituido por Friedmann, depois, de 70 para 80 , pelas escolas de expectativas racionais. Seu colapso é enquanto projeto político. Os reformadores keynesianos, simplesmente, desaparecem e com eles a idéia de que a manutenção do pleno emprego é uma obrigação dos governos (nos Estados Unidos e Inglaterra é uma obrigação legal. No pós-guerra, nos Estados Unidos, foi criada a lei do pleno emprego que obrigava o executivo a tomar medidas sempre que o desemprego ultrapasse um determinado ponto. Consideravam, nos anos 60 , pleno emprego uma taxa de $2 \%$ de desemprego. Nos anos 80 , a chamada taxa natural de desemprego é algumas vezes proposta a $7 \%$. No auge da recuperação americana, no ano passado, o desemprego caiu a 6,9\%).

É neste momento, porém, quando aos problemas de desemprego se somam pressōes inflacionárias, que se redescobre Keynes. Esta redescoberta foi proposta primeiramente por dois autores que trabalham nos Estados Unidos, Clower e Leijonhufvud. Eles tentaram recuperar Keynes, mas dentro da Teoria Convencional. O livro de 1968 de Leijonhufvud é todo dedicado à idéia de que existe uma diferença essencial entre a economia de Keynes e a síntese neoclássica, e que valeria a pena reestudar a economia de Keynes, tentando encontrar uma saida dos dilemas presentes. Através do levantamento das insatisfações que cercavam as alternativas como, por exemplo, as expectativas racionais, que não resolviam os problemas que se reabriu o debate, se redescobre a própria Teoria Geral.

Foi a partir de sua obra "O Tratado sobre a Moeda" - um livro

25 - Para uma exploração desta trajetória, veja-se F. Carvalho, "O Caminho da Revolução: O Treatise on Money na Revoluçăo Keynesiana", em C.M. Lopes et. al., Ensaios de Teoria Pós-Keynesiana, Fortaleza, UFCE, 1987.

26 - J.M. Keynes, CNJMK, vol. XIII, p.408/9. 
brilhante em certos pontos, mas coberto de incoerências -- que Keynes percebeu a necessidade de construir algo diferente. ${ }^{25}$ Em 33 Keynes definiu seu objeto de estudo, que ele chamou de "uma Ecomomia Monetária", como sendo o estudo de uma economia onde a moeda não é neutra. ${ }^{26}$ Essa afirmação é a síntese do que ele está buscando, ou seja, que a moeda faça diferença, que influa na determinação dos resultados do sistema, tanto no curto período, como, o que é ainda mais importante, no longo periodo. Algumas teorias admitem - inclusive a de Friedmann - que no curto período a moeda pode exercer alguma influência. No longo periodo, porém, não há ilusão monetária, na visão, convencional, que resista. O que Keynes quer porém é uma teoria que mostre haver influência de longo período, sem que se tenha que assumir ilusão monetária.

Keynes assume racionalidade tanto quanto qualquer outro autor. Não se propõe, como na ilusão monetária, a idéia de que as pessoas apegam-se ao metal ou a simples pedaços de papel impresso. A visão de economia que é proposta é que é diferente da trabalhada até então. Tanto na visão walrasiana quanto na Marshaliana encontramos o paradigma de Robinson Crusoé, exemplificado pela história de uma pessoa sozinha em uma ilha, escolhendo entre atividades "reais". Pode pescar e comer o peixe imediatamente ou, então, passar o dia sem comer, fazendo uma rede e ter muito mais peixes no dia seguinte. $O$ princípio da troca racional não necessita duas pessoas, basta uma. Troca-se entre o consumo presente e o consumo futuro. Para ter-se uma idéia de como esta abordagem era arraigada, em 36, Harrod publica um livro chamado "Ciclo Econômico" onde se discute uma questão típica da economia industrial avançada, que são as flutuaçōes ciclicas, iniciando pelo principio de Robinson Crusoé. No primeiro capitulo é discutido esse tipo de escolha, sendo este o procedimento usual.

Supor que o que é penalizar a uma economia capitalista caracterizada pela existência de produção industrial avançada pode ser abordado simplesmente, através de uma qualificação a princípios eternos e mutáveis - como os que explicarn a busca de satisfação de descontos individuais, como queria Walras era algo inaceitável para Keynes. Para este, teorias nascidas de tal concepção nunca seriam úteis ao estudo de economias monetárias, que demandavam o desenvolvimento de conceitos e instrumentos específicos. É exatamente, para isso que Keynes produz a Teoria Geral, o que fica muito claro na leitura dos volumes $13,14,29$ de suas obras e, em particular no texto chamado "Uma Teoria Monetária da Produção" citado acima (nota 26) onde ele anuncia o programa de pesquisa Keynesiana. A mensagem sugerida é 
a seguinte: uma economia monetária moderna nāo é a economia do individuo isolado, independente, maximizando satişfação pela escolha entre bens. Ela não é uma economia deste tipo, nem pode ser abordada como tal. As características destas economias monetárias não são apenas peculiaridades históricas, mas elas definem um tipo diferente de dinâmica econômica.

Não é possível: no tempo que me resta, explorar adequadamente as dimensões e implicações do conceito de economia monetária. As obras citadas na nota 24 , juntamente com a leitura dos volumes relevantes da obra de Keynes, podem mostrar aos leigos a importância daquela noção. Aqui faremos, apenas uma rápida discussão pelo tema.

São quatro as características desta economia monetária definidas por Keynes. Esta economia monetária - que recebe nomes diferentes em certos momentos - define-se inicialmente por uma distinção de agentes, tirando-a, imediatamente, da esfera de Robinson Crusoé. $\mathrm{Na}$ economia monetária existem trabalhadores e empresários, sendo esta diferença importante por várias razões. Por exemplo, em termo de decisões. As firmas, os empresários são os elementos que decidem em uma economia capitalista. Os empresários tem o poder decisório e dar mais ou menos empregos. Decisōes dos capitalistas são, qualitativamente, mais importantes do que a dos trabalhadores para a determinação da operação da economia.

A segunda característica crucial é o fato de que a função-objetivo destes dois agentes é, também, diferente. Os trabalhadores enquanto consumidores querem maximizar consumo, satisfaçāo, etc. Keynes não se opõe a essa idéia. Opõe-se, isto sim, à forma como isso é resolvido, em seu exame da propensão a consumir, mas não a idéia em si de que, basicamente, as pessoas buscam a satisfação. A funçãoobjetivo de firmas define-se, em contraste, em termos monetários. Firmas acumulam riqueza em forma de dinheiro. Uma empresa que produz e nấro vende, vai a falência. Não é a mesma coisa dizer-se que a riqueza real de uma determinada empresa são todos os estoques não vendidos. A empresa produz não porque está maximizando uma função-objetivo definida em termos reais, mas porque busca a acumulação de poder de compra em forma abstrata, em outras palavras, 0 acúmulo de dinheiro. Isto significa que há determinados tipos de agen-

27 - Isto implica que o sucesso de firmas em atingir seus objetivos está restrito năo apenas por teorias (restriçăo conhecida) mas também pelo citado dos mercados no momento da ven$\mathrm{da}$, variável incerta. Isto torna a produçấo uma economia monetária irremedlavelmente especulativa. Ver. J.M. Keynes, CNJMK, vol. XIX; H. Minsky, John Maynard Keynes, New York: Columbia University Press, 1975; J. Kregel, "Markets and Institution as Features of a Capitalistic Production System", Journal of Post Keynesian Economics, Fall 1980. 
tes pará os quais não há uma função consumo em termos de bens. Se se quiser definir comportamento em termos de solução a problema de maximização, deve ficar claro que não se está maximizando em termos de bens, está se, isto sim, maximizando em termos de valores e isso implica em um tipo de comportamento completamente diferente. ${ }^{27}$ Dentro de uma visão mais convencional, firmas não existem. Tem-se funções de produção, mas não se tem firmas. Nas poucas teorias comportamentais ortodoxas de firmas tenta-se usar as funçōes de utilidade dos gerentes numa tentativa de aproximação a essa solução. Para Keynes não são as necessidades de consumo dos gerentes, mas sim, as da firma enquanto uma instituição, sendo, portanto, um agente irredutivel, que contam. Dentro de uma economia capitalista a firma é um agente com objetivos próprios buscados de uma forma diferente daquela dos consumidores.

Uma segunda característica desta economia monetária é de existir, dentro dela, uma forma de prover-se o consumo futuro, não envolvendo ao compromisso com bens. Pode-se poupar para o futuro sem precisar encomendar mercadorias. Basta colocar-se no banco, ou em um país de moeda um tanto estável, bastaria entesourar. Ou seja, não se necessário decidir-se hoje sobre o consumo futuro, porque há uma alternativa. Esta saida é, obviamente, o dinheiro. Para Keynes, o dinheiro cria incerteza para os produtores, em função, exatamente, deste grau de liberdade que ela dá aos agentes. Se, quando decidir-se prover para o futuro, não há necessidade de encomendar-se os bens que se poderá comprar no futuro, firmas, conseqüentemente, não terão condições de prever o que produzir. Ou seja, elas não saberão em que linha de produção investir já que os consumidores não precisam decidir hoje o que irão comprar daqui a 10 anos. Tem-se que arriscar a formar expectativas sob incerteza. Em face disto é necessário procurar formas de defesa. Ou seja, na economia monetária, a moeda tem este papel, ela permite o adiamento de decisões, tornando-se, desta forma, uma fonte de incertezas de mercado.

A terceira caracteristica apenas vou citar, embora ela seja relevante dentro da teoria keynesiana na discussão de inflação. Trata-se da existência de contratos de moeda. ${ }^{28}$

A quarta caracteristica tem um papel relevante dentro da definição da economia monetária. Segundo Keynes, a moeda, que preenche a função de adiar as decisóes, é caracterizada pela baixa elasticidade de produção, elasticidade nula ou neglegivel. Ou seja, a oferta de moeda não é produtível por trabalho privado, significando que em uma

28 - Este ponto é extremamente importante, mas não pode ser tratado com brevidade. Para a discussáo adequada, veja-se P. Davidson, Money and the Resł World, cit. 
determinada situação, por exemplo, um empresário, ao sentir dificuldade na hora de escolher qual o tipo de investimento a fazer, pode decidir-se pela retenção de moeda. Com isso, os trabalhadores desempregados do setor de produção de bens de capital não serão reempregados na produção de moeda. Keynes define a elasticidade de produção da moeda como o coeficiente de utilização de trabalho em resposta a uma variação de demanda como zero ou quase zero. Esta é, para Keynes, a explicação de desemprego, não tendo nada a ver com rigidez de coisa alguma. A rigidez de salários ou a constância de salários é uma proposta política de Keynes. A proposta de estabilidade de preços em Keynes, calca-se na idéia de estabilidade dos salários nominais, porém, em nenhum momento, nenhum diagnóstico depende desta afirmação. Tudo o que é necessário para explicar o surgimento de desemprego, é a existência de um ativo irreprodutível que substitua um ativo reprodutivel, gerado uma deficiência de demanda efetiva pelo produto disponivel.

Encerrando, o esquema de economia monetária se apoia sobre os conceitos de incerteza e formação de expectativas sob incerteza. $\mathrm{Na}$ raiz, o conceito de incerteza surge, fundamentalmente, porque em uma economia monetária as demandas futuras não são pré-definidas e não há formas de organizar-se mercados futuros completos. A solução que nos dá Debreu é a utilização de mercados contingentes, em um esquema, que pode ser simplificado como fez Arrow. A idéia é a de que se especifique, de antemão, todas as possiveis transações futuras. Dentro da visão keynesiana, o mundo não funciona desta maneira. Os consumidores não agem assim já que a moeda os absolve desta necessidade. A moeda permite adiar essas decisões, com isto eliminando a informação que garantiria o pleno emprego. $O$ conceito de incerteza, em particular associado às decisões com um longo horizonte temporal, passa a ser central e é central exatamente porque a discussão aborda o efeito de longo periodo da moeda: se a moeda é um substituto para bens de investimento ela afeta os determinantes da acumulação capitalista. Isto é central em, Keynes, e o destaca, inclusive, das versões de natureza wickselliana. $O$ essencial, de qualquer forma, é que ele está propondo uma forma de se abordar a economia. Enquanto houve algo em comum entre esta forma de abordar e o que a sintese propunha, que era a preocupação com o desemprego e a eficácia da gerência de demanda de certas situações. Os resultados foram coincidentes. Mas o colapso da sintese, e essa é a proposta que eu, obviamente, espero que vocês examinem através dos textos originais não tem náda a ver com as limitações do próprio Keynes. A sintese neoclássica se mostrou, na verdade, insuficiente nos pontos exata- 
mente que se tornaram cruciais, a partir dos anos 60 , que foram a discussão de inflação, a discussão da própria estabilidade que se tornou intrínseca e permanente nas economias capitalistas, inclusive as mais desenvolvidas, dos anos 70 para cá. Nós temos alguma esperança de que nas obras de Keynes, não enquanto sagradas escrituras, mas enquanto proposta de uma nova visão de economia, se possa encontrar os argumentos para se entender os problemas atuais. A síntese, infelizmente, por mais útil que ela possa ter sido, efetivamente se esgotou. 